\title{
The Effects of Flow on Airway Pressure During Nasal High-Flow Oxygen Therapy
}

\author{
Rachael L Parke RN MHSc, Michelle L Eccleston RN, and Shay P McGuinness MB ChB
}

\begin{abstract}
BACKGROUND: Nasal high-flow oxygen therapy increases the mean nasopharyngeal airway pressure in adults, but the relationship between flow and pressure is not well defined. OBJECTIVE: To determine the relationship between flow and pressure with the Optiflow nasal high-flow oxygen therapy system. METHODS: We invited patients scheduled for elective cardiac surgery to participate. Measurements were performed with nasal high-flow oxygen at flows of 30, 40, and $50 \mathrm{~L} / \mathrm{min}$, with the patient's mouth both open and closed. Pressures were recorded over one minute of breathing, and average flows were calculated via simple averaging. RESULTS: With the mouth closed, the mean $\pm \mathrm{SD}$ airway pressures at 30, 40, and $50 \mathrm{~L} / \mathrm{min}$ were $1.93 \pm 1.25 \mathrm{~cm} \mathrm{H}_{2} \mathrm{O}, 2.58 \pm 1.54 \mathrm{~cm} \mathrm{H}_{2} \mathrm{O}$, and $3.31 \pm 1.05 \mathrm{~cm} \mathrm{H}_{2} \mathrm{O}$, respectively. There was a positive linear relationship between flow and pressure. CONCLUSIONS: The mean nasopharyngeal pressure during nasal high-flow oxygen increases as flow increases. (Australian Clinical Trials Registry http://www.adhb.govt.nz/achicu/ hot_2_airway_pressure.htm) Key words: nasal high-flow therapy; oxygen therapy; airway pressure. [Respir Care 2011;56(8):1151-1155. (C) 2011 Daedalus Enterprises]
\end{abstract}

\section{Introduction}

We use nasal high-flow oxygen therapy in the respiratory management of patients in the Cardiothoracic and Vascular Intensive Care Unit (ICU) at Auckland City Hospital, Auckland, New Zealand. With the Optiflow system (Fisher \& Paykel Healthcare, Auckland, New Zealand)

\footnotetext{
Ms Parke and Dr McGuinness are affiliated with the Cardiothoracic and Vascular ICU, Auckland City Hospital, Auckland, New Zealand. At the time of this study, Ms Eccleston was affiliated with the Cardiothoracic and Vascular ICU, Auckland City Hospital, Auckland, New Zealand. She is now affiliated with Fisher \& Paykel Healthcare, Auckland, New Zealand.
}

This study was partly supported by Fisher \& Paykel Healthcare, which provides some funding to the Auckland District Health Board for the research nurse's salary in the Cardiothoracic and Vascular ICU, Auckland City Hospital, and which provided some of the supplies used in the study and paid for the statistical analysis. Michelle Eccleston is now employed as clinical research scientist by Fisher \& Paykel Healthcare and is part of an employee-sharing arrangement.

Correspondence: Rachael L Parke RN MHSc, Cardiothoracic and Vascular Intensive Care Unit, Auckland City Hospital, Private Bag 92024, Auckland 1010, New Zealand. E-mail: rparke@adhb.govt.nz.

DOI: $10.4187 /$ respcare.01106 blended air and oxygen can be delivered nasally at flows up to $60 \mathrm{~L} / \mathrm{min}$, with the inspired gas heated to $37^{\circ} \mathrm{C}$ and humidified at $44 \mathrm{mg} \mathrm{H}_{2} \mathrm{O} / \mathrm{L}$. The patient interface is a wide-bore nasal cannula that is designed to be non-occlusive in the nares.

A previous study with cardiac surgery patients found that nasal high-flow oxygen at $35 \mathrm{~L} / \mathrm{min}$ delivered a mean airway pressure of $2.7 \mathrm{~cm} \mathrm{H}_{2} \mathrm{O}$, with the mouth closed. ${ }^{1} \mathrm{~A}$ study with healthy volunteers found that, at $40 \mathrm{~L} / \mathrm{min}$ from the Optiflow system, mean airway pressure was approximately $4.6 \mathrm{~cm} \mathrm{H}_{2} \mathrm{O} .^{2}$ Those 2 studies provide scant evidence to inform clinicians about the airway pressure generated by nasal high-flow oxygen and the effect of increasing the flow, so we studied the relationship between flow and pressure in cardiac surgery patients on the Optiflow system.

\section{Methods}

This was a prospective, descriptive study, undertaken in our tertiary-care Cardiothoracic and Vascular ICU. The study was approved by our regional ethics committee. The study was partly supported by Fisher \& Paykel, which supplied the Optiflow circuits and paid for the statistical analysis. The first author (RLP) designed the study and 


\section{The Effects of Flow on Airway Pressure During Nasal High-Flow Oxygen Therapy}

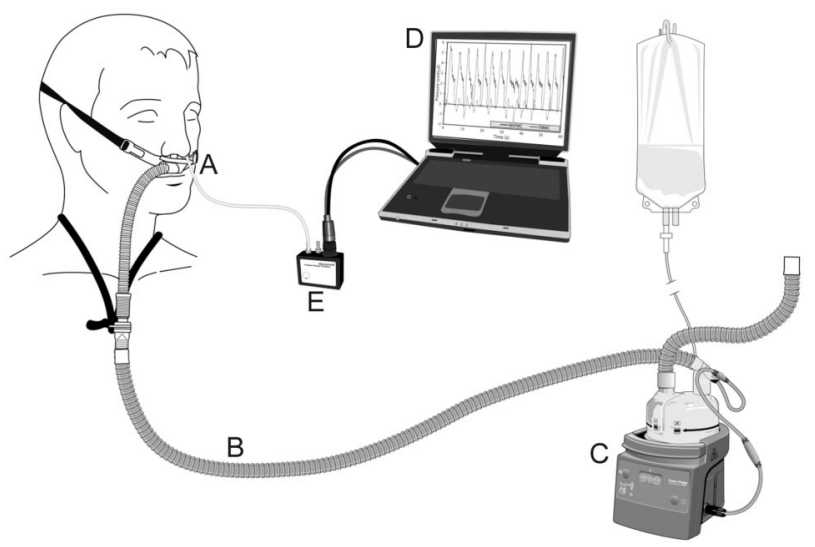

Fig. 1. Optiflow system. A: Cannula. B: Heated delivery tube. C: Heated humidifier. D: Laptop interface. E: Pressure transducer.

was primarily responsible for data collection, analysis, and writing the paper, in consultation with Fisher \& Paykel.

We invited 15 patients scheduled to undergo elective cardiac surgery to participate, and all subjects gave informed consent. Patients were excluded if there were contraindications to nasal high-flow oxygen. While patients were sedated and ventilated in the ICU after surgery, we inserted and secured a 10 French catheter into the nasopharynx, via the nose, where it remained overnight. The measurements were performed once the patient was awake, extubated, and sitting up in a chair.

We visually confirmed that the manometry catheter tip was just below the uvula. We also used end-tidal $\mathrm{CO}_{2}$ monitoring to confirm correct placement and catheter patency. The catheter was connected to a pressure transducer (PPT-0001 DWWW2VA B, Honeywell) connected to a laptop computer interface. As necessary, the catheter was adjusted or suctioned to obtain a clear reading.

The patient was started on nasal high-flow oxygen (RT033/034 Optiflow nasal cannula, MR880 heated humidifier, and RT241 heated delivery tube, Fisher \& Paykel Healthcare, Auckland, New Zealand) (Fig. 1) once the system reached the set temperature $\left(37^{\circ} \mathrm{C}\right)$. Therapy was established for 15 min prior to measurements, to allow the patient to become accustomed to the feeling of increased flow and to allow the breathing pattern to settle. Measurements were then performed with the patient's mouth open, and again with the mouth closed, at flows of 30,40 , and $50 \mathrm{~L} / \mathrm{min}$. Recordings were taken over one minute of quiet breathing. The order of measurements was determined with a Williams-design Latin square, so that each treatment occurred once per patient and there was balance for any carryover effect. ${ }^{3}$ This ensured random treatment allocation to each measurement, and sequences were randomly allocated to the patients, square by square.

Mean nasopharyngeal airway pressure was calculated by averaging the pressure from the peak of inspiration of
Table 1. Subjects $(n=12)$

\begin{tabular}{lc}
\hline \hline Age (y) & $64 \pm 12$ \\
Age range (y) & $40-84$ \\
Male, no. & 9 \\
Female, no. & 3 \\
Ethnicity, no. & 3 \\
$\quad$ Other European & 8 \\
$\quad$ New Zealand European & 1 \\
$\quad$ New Zealand Maori & $174 \pm 12$ \\
Height (cm) & $163-205$ \\
Height range (cm) & $86 \pm 19$ \\
Weight (kg) & $55-121$ \\
Weight range (kg) & \\
\hline values are mean \pm SD. & \\
\hline
\end{tabular}

the first breath to the peak of inspiration of the last breath during the one-minute recording, so the entire pressure profile of each breath in that one minute was included in the pressure calculation.

Data analysis was performed with spreadsheet software (Excel 2003, Microsoft, Redmond, Washington) and statistics software (SAS 9.1.3, SAS Institute, Cary, North Carolina, and R 2.8.1, R Foundation for Statistical Computing, Vienna, Austria). We used the paired $t$ test to compare the mean differences. To assess the relationship between flow and mean airway pressure we used a mixed linear regression model in which the mean pressure was the response, flow was the predictor, and "patient" was a random effect to account for the intra-patient variance, because each patient had measurements at 30,40, and $50 \mathrm{~L} / \mathrm{min} . P<.05$ was considered statistically significant. Data are presented as mean $\pm \mathrm{SD}$.

\section{Results}

We recruited 15 patients, of whom 12 completed the study (Table 1). The reasons for failure to complete the study were: we could not pass the manometry catheter due to epistaxis (one patient); the patient dislodged the catheter prior to measurement (one patient); the patient required prolonged ventilation, so we electively removed the manometry catheter.

Figure 2 and Table 2 show the mean pressure measurements. Between mouth open and mouth closed there were statistically significant pressure differences at each flow. There was a positive linear relationship between flow and pressure (Fig. 3). With mouth open, the slope was lower than with mouth closed. Using this regression model, in the mouth-closed position, for every $10 \mathrm{~L} / \mathrm{min}$ increase in gas flow, the mean pressure increases by $0.69 \mathrm{~cm} \mathrm{H}_{2} \mathrm{O}$ $(P=.01)$. In the mouth-open position, for every $10 \mathrm{~L} / \mathrm{min}$ 


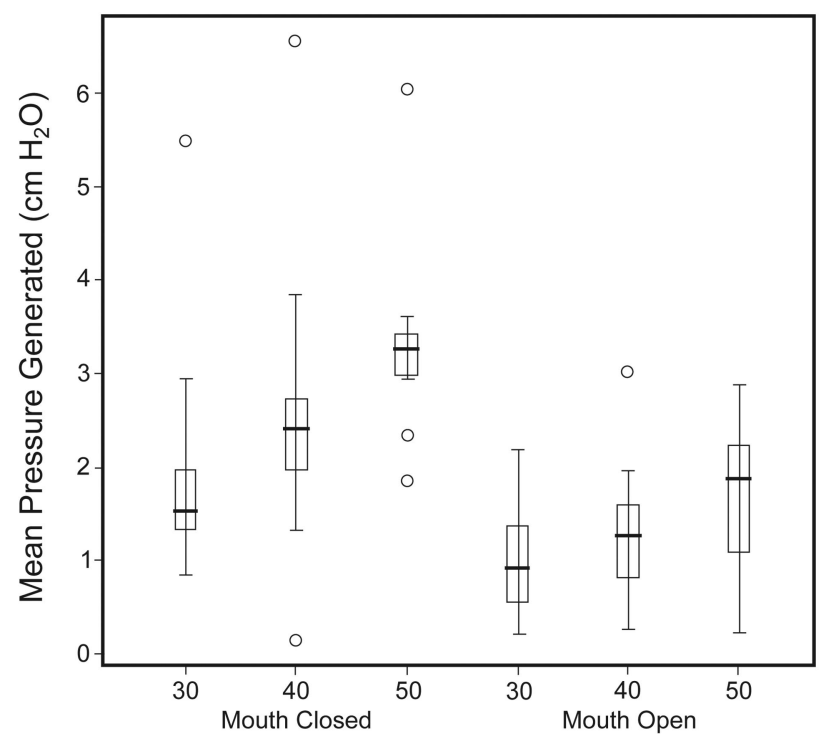

Gas Flow Delivered (L/min)

Fig. 2. Mean nasopharyngeal pressure during high-flow oxygen therapy, with mouth open or closed. The horizontal line in the middle of each box indicates the median, while the top and bottom borders of the box mark the 75th and 25th percentiles, respectively. The whiskers above and below the box mark the 90th and 10th percentiles. The points beyond the whiskers are outliers beyond the 90th or 10th percentiles.

Table 2. Airway Pressure During Nasal High-Flow Oxygen With the Optiflow System

\begin{tabular}{lccc}
\hline \hline $\begin{array}{c}\text { Flow } \\
(\mathrm{L} / \mathrm{min})\end{array}$ & $\begin{array}{c}\text { Mouth Closed } \\
\left(\mathrm{cm} \mathrm{H} \mathrm{H}_{2} \mathrm{O}\right) \\
\text { mean } \pm \mathrm{SD}\end{array}$ & $\begin{array}{c}\text { Mouth Open } \\
(\mathrm{cm} \mathrm{H} \mathrm{O}) \\
\text { mean } \pm \mathrm{SD}\end{array}$ & $P$ \\
\hline 30 & $1.93 \pm 1.25$ & $1.03 \pm 0.67$ & .046 \\
40 & $2.58 \pm 1.54$ & $1.30 \pm 0.80$ & .03 \\
50 & $3.31 \pm 1.05$ & $1.73 \pm 0.82$ & $<.001$ \\
\hline
\end{tabular}

increase in gas flow, the mean pressure increases by $0.35 \mathrm{~cm} \mathrm{H}_{2} \mathrm{O}(P=.03)$.

\section{Discussion}

We found a positive linear relationship between the flow delivered and the mean airway pressure generated during nasal high-flow oxygen in cardiac surgery patients. For every unit increase in flow, there is a resulting increase in the mean airway pressure generated, and the most airway pressure is generated with the mouth closed. These findings correlate well with previous studies. ${ }^{1,2,4}$

We believe that one of the mechanisms for this positive airway pressure is the resistance to expiration that is generated by the patient breathing out against the continuous incoming gas flow. This is evidenced by the higher pressure when the patients breathed with their mouths closed.

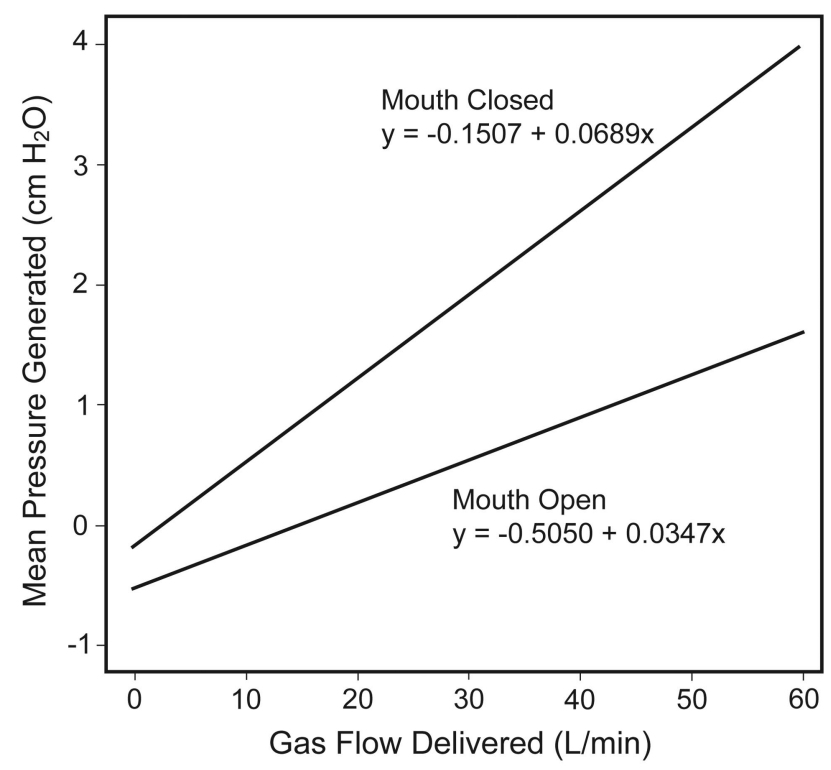

Fig. 3. Regression analysis of mean nasopharyngeal pressure during high-flow oxygen therapy, with mouth open or closed.

It is logical to assume that with the mouth closed the resistance to expiration is significantly higher due to the restricted path through which the expired gas must flow. It also seems reasonable to suggest that as the incoming gas flow increases, the patient must generate higher expiratory pressure to overcome the opposing force of the incoming gas. However, from our observations and those of other authors, the pressure effect does not seem to be limited to expiration. Groves and Tobin found a significant increase in pressure during inspiration. ${ }^{2}$ One explanation for this may be that the high velocity of incoming gas pressurizes the upper airway above atmospheric pressure, which can be clearly observed on the pressure profile.

In this study, as in the previous study, the pressure profiles generated with nasal high-flow oxygen show a general pressure elevation in both the inspiratory and expiratory phases. Figure 4 shows the pressure profiles from one patient during nasal high-flow oxygen at 30,40 , and $50 \mathrm{~L} / \mathrm{min}$, with mouth-open and mouth-closed breathing. A previous study found "normal" pharyngeal pressure profiles in patients breathing with high-flow face mask, and that these tend to rotate around atmospheric pressure. ${ }^{1}$ All of the pressure profiles from the patient in Figure 4 are above normal throughout the respiratory cycle, though there are some small dips below atmospheric pressure at the peak of inspiration, which perhaps differentiate nasal highflow oxygen from continuous positive airway pressure. This observation was fairly typical in this study group.

As in similar studies, ${ }^{1,2,4}$ we found some inter-patient variability in airway pressure in patients using the Optiflow system (see Fig. 2). We hypothesize that anatomical and physiological differences between patients affect the 

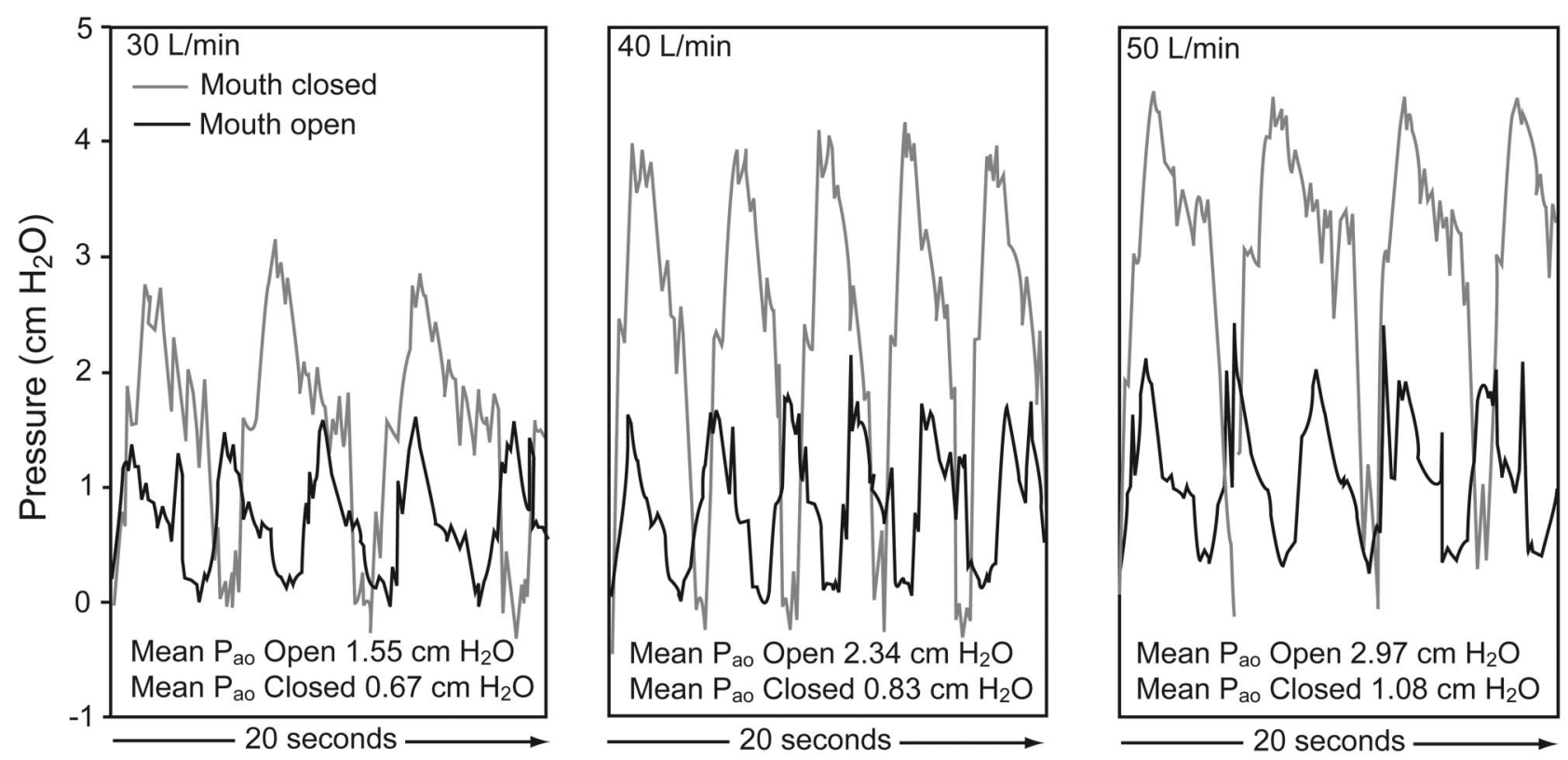

Fig. 4. Example airway pressure profiles from one patient, with mouth open or mouth closed, at flows of 30, 40, and 50 L/min.

resistance to expiration and therefore the airway pressure. Groves and Tobin reported that females had significantly higher airway pressure than males with the Optiflow system. ${ }^{2}$ Because of the small number of female participants in the present study, we were unable to test for sex differences. The size of the patient's nares relative to the nasal interface may be the greatest cause of variability. Clinicians should be aware of inter-patient variability when prescribing nasal high-flow oxygen.

We propose that nasal high-flow oxygen may extend the role of oxygen therapy by delivering low-level positive airway pressure. Traditionally, a tightly fitted nasal or oronasal mask has been needed to noninvasively deliver any positive airway pressure. However, nasal high-flow oxygen is not proposed as an alternative to continuous positive airway pressure or noninvasive ventilation, where controlled pressures are indicated, but nasal high-flow oxygen might be a bridge to these therapies in selected patients. Given some of the reported issues associated with sealed mask therapies (mask discomfort, nasal dryness, oral dryness, eye irritation, nasal or eye trauma, gastric distention, and aspiration ${ }^{5,6}$ ) nasal high-flow oxygen may have an important role. There is limited evidence of better clinical outcomes with nasal high-flow oxygen. One preliminary randomized controlled trial found that significantly more patients allocated to nasal high-flow oxygen were considered to be successful in their treatment arm than those allocated to high-flow humidified face mask $(P=.006){ }^{7}$ Also the rate of noninvasive ventilation in the nasal highflow oxygen group was $10 \%$, compared to $30 \%$ in the face-mask group $(P=.10)$; however, the study was not powered to detect that outcome. ${ }^{7}$
In comparison to high-flow face-mask oxygen, 2 recent studies found better comfort, tolerance, and oxygenation, and lower respiratory rate with nasal high-flow oxygen. ${ }^{8,9}$

In addition to a low-level pressure effect, other proposed mechanisms of action may include the ability to more accurately control the patient's $\mathrm{F}_{\mathrm{IO}_{2}},{ }^{4,10}$ flushing of anatomical dead space, ${ }^{11}$ and better mucociliary clearance. ${ }^{12}$ The extent to which each mechanism affects physiological outcomes and therapy efficacy remains to be determined.

\section{Limitations}

One limitation of this study may be that we used nasopharyngeal manometry rather than esophageal manometry. Reasons for employing nasopharyngeal manometry included the perceived difficulties and acceptability of using this technique in conscious patients. To further describe the impact of nasal high-flow oxygen on respiratory mechanics and work of breathing we suggest repeating this study with esophageal manometry, respiratory plethysmography, or electrical impedance tomography. To reduce the duration of the study procedure, we chose not to record baseline measurements with zero flow, which may be a limitation. A final limitation is the small sample size $(n=12)$, which limits the generalizability of our results. However, we feel the study is valid and adds to the body of evidence on nasal high-flow oxygen.

\section{Conclusions}

In cardiac surgery patients, there was a positive linear relationship between flow and airway pressure during na- 


\section{The Effects of Flow on Airway Pressure During Nasal High-Flow Oxygen Therapy}

sal high-flow oxygen with the Optiflow system. These results may inform practice and facilitate titration of flow. This study adds to the growing body of literature on nasal high-flow oxygen, but there remains a paucity of clinical outcome evidence on this novel therapy.

\section{ACKNOWLEDGMENTS}

We thank Heidi Buhr RN, Cardiothoracic and Vascular Intensive Care Unit, Auckland City Hospital, Auckland, New Zealand, for assistance with this study.

\section{REFERENCES}

1. Parke R, McGuinness S, Eccleston M. Nasal high-flow therapy delivers low level positive airway pressure. Br J Anaesth 2009;103(6): 886-890.

2. Groves N, Tobin A. High flow nasal oxygen generates positive airway pressure in adult volunteers. Aust Crit Care 2007;20(4):126131.

3. Jones B, Kenward MG. Design and analysis of cross-over trials. London: Chapman and Hall; 1989
4. Williams AB, Ritchie JE, Gerard C. Evaluation of a high flow nasal oxygenation system: gas analysis and pharyngeal pressures. Int Care Med 2006;32(Suppl 1):S219.

5. Hill NS. Complications of non-invasive positive pressure ventilation. Respir Care 1997;42(4):432-442.

6. Evans TW. International Consensus Conferences in Intensive Care Medicine: non-invasive positive pressure ventilation in acute respiratory failure. Intensive Care Med 2001;27(1):166-178.

7. Parke RL, McGuinness SP, Eccleston ML. A preliminary randomized controlled trial to assess effectiveness of nasal high flow oxygen in intensive care patients. Respir Care 2011;56(3):265-270.

8. Tiruvoipati R, Lewis D, Haji K, Botha J. High-flow nasal oxygen vs. high-flow face mask: a randomized crossover trial in extubated patients. J Crit Care 2010;25(3):463-468.

9. Roca O, Riera J, Torres F, Masclans J. High-flow oxygen therapy in acute respiratory failure. Respir Care 2010;55(4):408-413.

10. Sim MA, Dean P, Kinsella J. Performance of oxygen delivery devices when the breathing pattern of respiratory failure is simulated. Anaesthesia 2008;63(9):938-940.

11. Dysart K, Miller TL, Wolfson MR, Shaffer TH. Research in high flow therapy: mechanisms of action. Respir Med 2009;103(10):1400 1405.

12. Hasani A, Chapman TH, McCool D, Smith RE, Dilworth JP, Agnew JE. Domiciliary humidification improves lung mucociliary clearance in patients with bronchiectasis. Chron Respir Dis, 2008;5(2):81-86. 